\title{
Proprioceptive training in dance sport: effects of agility skills
}

\author{
Adriana Ljubojevic ${ }^{1} \oplus$, Boris Popovic ${ }^{2} \oplus$, Snezana Bijelic ${ }^{1} \oplus$, Sasa Jovanovic ${ }^{1} \oplus$ \\ ${ }^{1}$ University of Banja Luka, Faculty of Physical Education and Sport, Bosnia and Herzegovina. ${ }^{2}$ Faculty of Sport and Physical \\ Education, University of Novi Sad, Serbia.
}

\begin{abstract}
The aim of this research is to determine the effects of proprioceptive training on the improvement of agility skills in dance sport fitness conditioning. Proprioceptive training is realized throughout tasks that include the establishing and maintaining various positions on balance boards of different dimensions, working surfaces and platforms. 38 male and female competitive dancers divided into an experimental and control groups. The experimental group took part in a proprioceptive training program over a period of 12 weeks ( $3 \times 30$ minutes per week). The control group (at the same time as the experimental) had regular sport dance training. At the beginning and at the end of the experiment, agility skills were measured by means of three different agility tests: Side steps, Figure ' 8 ' with bending and Agility in the air. Statistically significant differences among the groups in the final measurement $(p=.00)$ generally show a positive effect of the proprioceptive training program on the improvement of agility skills with the experimental group, especially in tests Figure ' 8 ' with bending and Side steps. Such findings could encourage the use of proprioceptive training model in daily dance classes due to its potential to improve dancers' agility skills. Therefore, the use of a proprioceptive training model, as an innovative approach in individual and group dance fitness conditioning is recommended.
\end{abstract}

Keywords. Agility, dance, movement awareness.

\section{Inroduction}

Proprioception is an ongoing topic of interest in dance research. Over the last years, the proprioceptive training has taken a more important role in fitness conditioning. The modern approach of developing fitness training in dance gives a great significance to the proprioceptive training program (Chatzopoulus et al., 2018; Jola et al., 2011; Ljubojevic et al., Srdic \& Bajric, 2015). Proprioception is inborn "talent" for body awareness and knowing just where the body is positioned in space or, more related to dancers, ability to acknowledge the body movements (Batson, 2009). Dancers might be more accustomed to related terms to define this sense, such as "kinaesthesia", muscle sense, body awereness or simply sense of movement. Curently, both proprioception and kinaesthesis are used interchangeably as terms in the relevant literature (Han et al., 2016; Rosker \& Sarabon, 2010). Dance is an art form that combines aesthetic characteristic with physical abilities such as postural control and static and dynamic balance. Proprioception mechanisms play essential roles in regulating balance by way of neuromuscular control (Tekin et al., 2018). The proprioceptive system, in general, enables the correct functioning of the locomotor apparatus during movement and sport activities, maintains muscle tonus and helps us to precisely differentiate isolated body moves that are particularly attractive in dancers choreographies. Latin and standard sport dancers have to demonstrate the perfect synthesis between technique, artistic skills and athleticism in order to give the best performance (WDSF, competition rules) . 
Understanding proprioception and thus developing apropriate proprioceptive training in dance sport fitness conditioning could increase body awareness, provide better dance performance and, also, decrease the risk of injury occurrance (Batson, 2009). Using this training method, among others, could help in easier overcoming aestetical and physical demands of dance sport performance. Also, reducing possibilities of injury can prolong the dancing career.

In recent years, there is a different approach to the study of proprioception in dance field such as joint position sense and injury occurrence (Esen et al., 2013) and muscle activation and coordination between two joints in relation to specific dance movements (Bronner, 2012; Golomer et al., 2008). Very popular researches are about balance improvement and balance efficiency (Hackney \& Earhart, 2010; Ambegaonkar et al., 2013; daSilva Borgers et al., 2014), or effect of vision compared to non-vision on balance maintenance (Bruyneel et al., 2010; Hutt \& Redding, 2014). Researches were comparing either two levels of dancers (Rein et al., 2011) or dancers' and non-dancers' (Ambegaonkar et al., 2013; Jola et al., 2011). The results show that dancing may improve balance as compared with not dancing. There are some studies about spatial awareness (Minton \& McGill, 2011) and whole body coordination (Miura et al., 2011). The study investigated whole-body sensorimotor synchronization (SMS) in street dancers and non-dancers. These findings suggest that down and up movements are two distinguishable coordination modes in wholebody coordination, and that street dancers have superior whole-body SMS ability. There are very interested studies about creative dance and proprioception on preschool children (Chatzopoulos et al., 2018). Authors concluded that creative dance can positively affect proprioception and rhythmic synchronization in preschool children. Unfortunately, there are very few studies on, particular, Latin and standard sport dancers
(Han et al., 2014, Ljubojević et al., 2012; Ljubojevic et al., 2017). Some studies show a positive effect of proprioceptive training on improving motor skills such as static and dynamic balance skills (Hutt et al, 2014; Ljubojević et al., 2012; Myer et al., 2006, Tekin et al., 2018). Identifying different factors that may affect the performance of the dancers is vital for protecting their health and improving the technical level of dancers. Body agility is very important motor skill in dance performance. Agility is the ability to change the body's position efficiently, and requires the integration of isolated movement skills using a combination of static and dynamic balance, coordination, speed, strength and endurance. Sheppard \& Young (2006) defined agility as a rapid whole body movement with the change of speed or direction in response to a stimulus. That "stimulus" in dance sport relates to other dancers on the dance floor, dance partner and, especially, complexity of choreography. Proprioceptive training has shown its positive influence on certain agility tests (Malliou et al., 2004). While proprioception training use is increasing in popularity, current research is lacking regarding the use of proprioceptive exercise as an effective option for increasing agility ability in dance sport. Thus, the aim of this research is to determine the effects of proprioceptive training on agility skills among dancers. The movement tasks within the selected agility tests correspond to the movement character in the dance choreographies: change of movement direction, spatial perception, muscle tension and speed control. The agility in sport dance choreographies is manifested most in small spatial movements in relation to the dance partner and according to the dance figures. The intent of this research is to contribute to the small number of researches about proprioceptive training in dance sport fitness conditioning. The expected results are important because they could redirect the traditional opinion that this type of training 
belongs only to preventive, maintaining and rehabilitation fitness programs.

\section{Methods}

\section{Participants}

The sample of participants consisted of 38 Latin and standard sport dancers, male and female, aged 15-19, divided into two groups: an experimental (E, $n=19 ; 11$ female and 8 male dancers) and control (C, n=19, 12 female and 7 male dancers) group. The participants are active competitors of the World Dance Sport Federation. They have been involved in the training process for at least seven years with a minimum of four training sessions per week (min 2 hrs/day). Consent to participate in the study was obtained from the parents of the children. All dancers volunteered to the testing procedures and we informed them regarding the potential risks associated with the applied testing protocol and gave written informed consent to the experiment. Both the consent and the experimental procedure were in accordance with the Declaration of Helsinki and approved by the Institutional Review Board of the Faculty of Physical Education and Sport, University of Banja Luka.

\section{Procedure}

This study includes the variables of agility skills such as Side steps (SS), Figure ' 8 ' with bending (FEB) and Agility in the air (AA). Agility variables were covered with 3 standardized motor tests (Metikoš et al., 1989) with necessary metric characteristics. All of the tests were measured in a sport hall with the same investigator. Each participant had three attempts per test and the best one was taken into consideration. The tests are here described in shortest possible way: Side steps (SS) shuffle side steps side-to-side between parallel lines $4 \mathrm{~m}$ (6 lengths in total); Figure of eight with bending (FEB) -movements between and around two cones or stands $4 \mathrm{~m}$ apart connected by elastic ribbon at the participant's shoulder height; a subject should run a figure of eight when passing under the ribbon. The task is completed when two figures are performed (Metikoš et al., 2003): Agility in the air (AA) - the four mats are placed so that they touch the wider sides. Then the two mats are separated so that 4 medical balls can be placed between them (to close the surface of the square). The subject turns his back to the medical balls and sits on the "back" of the two medical balls, and stretches his legs over the "front" of the balls. The subject should make the backward roll as fast as possible, get up and make the forward roll over the medics. The rolling is performed without touching the balls. After forward roll, the subject turns $180^{\circ}$ and touches all 4 balls with his palms.

\section{The Proprioceptive Training Program}

The proprioceptive training program was based on previous investigations and observations from conditioning coaches and sports medicine professionals (Myer, 2005; Filipa, 2010; Barlow, 2017). Before the experimental period none of the dancers had experienced unstable surfaces such as stability trainers or rocker boards. Therefore a familiarization session was conducted. In addition, one week preparatory pre-training period allowed participants to become accustomed to the following protocols and exercises. Proprioceptive experimental program model was conducted in a 12-week (36 training sessions). All exercises were performed barefoot to allow optimal proprioceptive input (Lieberman, 2012). Experimental group had three proprioceptive trainings sessions per week with different duration, depending on the level of difficulty. Also, they had regular technique and performance training sessions four times a week. Maximal duration of proprioceptive training (performance, pause between tasks, change of balance boards etc.) did not exceed 30 minutes. Experimental program was conducted before the dance training, but after specific warm-up exercises. The dancers performed a regular warm-up, consisting of 3- 
$5 \mathrm{~min}$ of jogging and $3-5 \mathrm{~min}$ of dynamic movements. During proprioceptive training, balance boards of various dimensions, working surfaces and platforms were used: moving roller, T-board, semi-roller, semi-ball, asymmetrical cone, "Bosu" ball, Pilates ball, soft mat and unstable polygons. The duration and number of repetitions were determined by the difficulty of tasks. On the other hand, difficulty was determined by the body position during exercising, jumps on balance plate, distractions during exercising, and use of different additional props, which made the performance harder in particular body positions (tennis balls, balls for rhythmic gymnastics, medical balls). Certain tasks were made with eyes closed and at a specific tempo of music. Examinees were organized in several unstable polygons where they worked out in pairs on one balance plate. The total time of one proprioceptive training (its realization) per examinee did not exceed 10 minutes, in order to avoid nerve-muscular fatigue. While experimental group had both proprioceptive and dance trainings, control group had only regular dance trainings, four times a week. During the proprioception tasks, proper body posture is required.

\section{Statistical Analysis}

All statistical analyses were performed using SPSS 20 (IBM, Armonk, NY). The level of statistical significance was set at $p<.05$. Kolmogorov-Smirnov test revealed that none of the dependent variables significantly deviated from normal distribution. Descriptive statistics were calculated as mean, standard deviation, minimum and maximum scores. Levene's test was used to test the homogeneity of variance of errors. The Univariate Analysis of Variance is used as the quantitative indicators for testing the significance of group differences in the initial and final measurement. The Multivariate Analysis of Covariance (MANCOVA) and Univariate Analysis of Covariance (ANCOVA) were used to determine the existing effects of proprioceptive training at the final measuring. Covariates are added so that it can reduce error terms and so that the analysis eliminates the covariates' effect on the relationship between the independent grouping variable and the continuous dependent variables. MANCOVA is a statistical technique that is the extension of ANCOVA. Basically, it is the MANOVA with a covariate(s).

\section{Results}

Table 1 presents the information on average value of arithmetic mean of $\mathrm{E}$ and $\mathrm{C}$ group obtained at the pre-test and post-test. All of the tested agility skills of the experimental group show decreased Mean values in the post-test measuring. The most different Mean values pre- and post-test measuring of the experimental group was noticed in the Side steps test (Mean=2.0).

Table 1

Descriptive statistics of pre-test and post-test of Control and Experimental group (Mean \pm SD).

\begin{tabular}{|c|c|c|c|c|c|c|c|}
\hline \multirow{2}{*}{ Groups } & \multirow{2}{*}{ Test } & \multirow{2}{*}{ Pre-test } & \multirow{2}{*}{ Post-test } & \multicolumn{2}{|c|}{ Pre-test } & \multicolumn{2}{|c|}{ Post-test } \\
\hline & & & & Min & Max & Min & Max \\
\hline \multirow[t]{3}{*}{ Control Group } & SS & $10.67 \pm 0.55$ & $10.37 \pm 0.65$ & 9.91 & 11.47 & 9.50 & 11.24 \\
\hline & FEB & $21.44 \pm 1.78$ & $20.97 \pm 1.49$ & 19.59 & 24.37 & 18.50 & 23.60 \\
\hline & AA & $4.14 \pm 0.52$ & $4.29 \pm 0.60$ & 3.55 & 5.28 & 3.62 & 5.32 \\
\hline \multirow[t]{3}{*}{ Experimental Group } & SS & $10.70 \pm 0.82$ & $8.70 \pm 0.81$ & 9.22 & 11.78 & 7.00 & 9.90 \\
\hline & FEB & $20.66 \pm 1.36$ & $19.36 \pm 1.58$ & 17.75 & 22.57 & 16.01 & 21.11 \\
\hline & AA & $4.04 \pm 0.51$ & $3.75 \pm 0.40$ & 3.29 & 4.98 & 3.00 & 4.17 \\
\hline
\end{tabular}

SD: Standard Deviation; SS: Side steps; FEB: Figure ' 8 ' with bending; AA: Agility in the air. 
Table 2

Levene's test for homogeneity of variance in errors of dependent variables.

\begin{tabular}{lcccc}
\hline Variables & $F$ & df1 & df2 & $p$ \\
\hline AA & 1.14 & 1 & 34 & 0.29 \\
\hline FEB & 0.01 & 1 & 34 & 0.91 \\
\hline SS & 1.59 & 1 & 34 & 0.21 \\
\hline
\end{tabular}

Levene's test showed the null hypothesis that the error variance of the dependent variable is equal across groups.

Table 3

The univariate analysis of variance results between the control and experimental group at the pre-test and post-test.

\begin{tabular}{llcccc}
\hline & Test & MS effect & MS Error & $F$ & $p$ \\
\hline Pre-test & SS & .099 & .493 & .019 & .89 \\
\cline { 2 - 6 } & FEB & 5.460 & 2.52 & 2.16 & .15 \\
\cline { 2 - 6 } & AA & .092 & .269 & .342 & .56 \\
\hline \multirow{3}{*}{ Post-test } & SS & 25.23 & .55 & 45.89 & .00 \\
\cline { 2 - 6 } & FEB & 23.39 & 2.37 & 9.85 & .00 \\
\cline { 2 - 6 } & AA & 2.58 & .26 & 9.82 & .00 \\
\hline
\end{tabular}

\section{Table 4}

Testing the significance of the effects of proprioceptive training on the agility using the multivariate analysis.

\begin{tabular}{ccccc}
\hline Wilks Lambda & $\mathrm{F}$ & $\mathrm{df1}$ & $\mathrm{df2}$ & $\mathrm{p}$ \\
\hline .326 & 19.95 & 3.00 & 29.00 & .00 \\
\hline
\end{tabular}

\section{Table 5}

Testing the significance of the effects of proprioceptive training on the agility by using a univariate analysis.

\begin{tabular}{lcccccc}
\hline Test & Adjusted Mean C & Adjusted Mean E & MS Effect & MS Error & F & $p$ \\
\hline AA & 4.00 & 3.79 & .29 & .12 & 2.35 & .13 \\
FEB & 20.60 & 19.41 & 9.07 & 1.40 & 6.46 & .01 \\
SS & 10.57 & 8.83 & 19.44 & .45 & 43.23 & .00 \\
\hline
\end{tabular}

As shown in Table 2, $p>.05$ indicates normal distribution of data and homogeneous variance of errors.

Data in Table 3 shows tested univariate analysis between the groups achieved at the pre-test and post-test. The results showed a statistically significant interaction at the posttest measurement between the control and experimental group in all observed agility tests $(\mathrm{SS} p=.00$; FEB $\mathrm{p}=.00$; AA $p=.00)$.
Data in Table 4 shows the effectiveness of proprioceptive training on agility using the MANCOVA. These statistical procedures have analysed the inter-group interaction at the post- test measurement with neutralization of any differences between the experimental and control groups at the pre-test measurement. The result has shown statistically significant $(p$ $=.00$ ) inter-group interaction. 
Individual univariate inter-group interactions in all the tests are determined using a univariate analysis of covariance (ANCOVA) see in Table 5 . The greatest contribution to group differences in the final measuring in favour of the experimental group was noted for the Side steps tests $(F=43.23)$ and Figure ' 8 ' with bending $(\mathrm{F}=6.46)$.

\section{Discussion}

The results of the present study revealed significant improvements in agility skills resulting from the long term effect of the applying proprioceptive training in dance sport fitness conditioning. The main findings of the present study were that twelve weeks of proprioceptive training exercises (3 days/wk, $30 \mathrm{~min} /$ day) significantly increased tested agility skills of dancers (Side steps $22.98 \%$; Figure " 8 " with bending $6.71 \%$; Agility in the air $7.73 \%$ ). Also, during a 12 -week period, the traditional sport dance technique classes alone were not enough to improve the agility performance.

Agility is a complex motor skill that depends on a number of factors which determine the locomotion efficiency. It primarily depends on coordination, the mobility of the joint system, the dynamic balance, strength, elasticity, speed, stability of the locomotor apparatus, and the optimal biomechanical movement structure (Verstegen \& Marcello, 2001). The movement structures within the applied proprioceptive training are implemented on balance boards that initiate the plantar and dorsal (anterior-posterior) flexion movements, and medio-lateral movements (inversion - eversion) and thus contributes to the improvement of the ankle muscle strength. This undoubtedly provides a better body control in the sudden changes of movement direction as it is required in the tests. Increased elastic muscle strength of the ankle, caused by long-term repetition of this movement, has resulted in shorter contact with the ground, which further caused quicker body weight transfer and better control in the change of movement direction. Applied proprioceptive training, also, included dynamic balance exercises that have influenced on joint mobility system better and more efficiently (Islam et al., 2004; Tekin et al., 2018) and exercises for better stabilization of locomotion (Hoffman \& Payne, 1995). It is assumed that through proprioceptive tasks, dancers have been trained to have better kinaesthetic sense. This enables more awareness in controlling all specific movements in dance choreographies. At a subconscious level, kinaesthetic sense retains muscle tonus, which automatically affects joint stabilization and the maintenance of a more balanced position. It is especially expressed in situations of sudden changes in muscle contractions caused by unexpected changes in the movements of the entire body or some of its parts. Without this inner sense of timing and accuracy, the injury rate would be a lot higher, and of course, simple movements would require an enormous amount of cognitive energy. It is assumed, also, that faster data transfer can be achieved throughout "afferent" and "efferent" paths. That would result in the momentary activation or inhibition of certain muscle groups which provide effective movement (Bruhn et al., 2004). By proper coordination of the obtained information, we can influence the efferent and reflex paths through which muscle tension is being regulated. In addition, we could also accomplish better coordination of agonist and antagonist muscles, providing information about dynamic stability and ease of movement.

A very important aspect of proprioceptive training for dancers is the fact that without establishing and maintaining proper body posture neither of the unstable tasks would be completed correctly. This can be achieved by mobilizing all the body's muscles and by intramuscular coordination. It is assumed that proprioceptive exercises increase dancer's awareness of the inclusion of certain muscle groups in establishing better body posture. 
Previous findings suggest that dance technique classes alone are not sufficient for development of certain motor skills such as dynamic balance and that proprioceptive training can be very effective in improving the balance performance of modern dancers (Tekin et al., 2018).

Movements in dance sport choreographies (Latin-American and standard dances) are based on a precisely dosed transfer of body weight from one leg to another, determined by the tempo of music. Considering this, only dance couples who can demonstrate very good alignment can be dominant in all progressive movements on the dance floor. Such a dance performance surely depends on agility skills. Predominant reason for studying proprioception in dance sport training process, for dance researchers, is to understand the functioning of the body better. Proprioception in dance sport already revealed the positive effects of this kind of training on the improvement of balance skills (Ljubojević et al., 2012). Some studies even show positive effects of proprioceptive training on agility skills of untrained individuals (Malliou et al., 2004). Research about the effects of proprioceptive training in dance sport fitness conditioning is very important considering how much agility skills affect dancers' performance.

\section{Conclusion}

The results of the present study revealed very useful information about applying proprioceptive training in dance sport fitness conditioning. The present study on the effects of proprioceptive training on agility points out to its statistically significant developmental effect. This research is a continuation of the study of the effects of this training model in the dance sport fitness conditioning since developmental effect on balance skills has already been proven (Ljubojević et al., 2012). Affirmation of the proprioceptive training model in dance sport could redirect dance fitness conditioning to more "body movement awareness" and less "functional development". They could enrich the previous perception of the training approach in dance sport and add proprioceptive training as a training model that would mark new guidelines in individual as well as group fitness conditioning of dance sport performers. The fact that this training concept could be applied in other fields of sport with similar conventional structural movements with an emphasized aesthetic criteria, where precisely dosed and controlled progressive movements are particularly significant (skating, synchronized swimming, rhythmic gymnastics, and so on) is one of the practical benefits of this research. Dance researchers have begun to realise the importance of studying proprioception, and have done so among various age groups, dance styles, and contexts. Future aproach of proprioception in dance sport should be directed to further understanding of proprioceptive learning and thus develop adequate proprioceptive training models for dance sport performance. In future research, it would be interesting to investigate proprioceptive effect on some competition aspect of dance sport performance such as technical qualities, movement to music, partnering skill, etc. (WDSF Judging System, 2014). The limitation of this study are reflected in the small number of male dancers and hence gender differences could not be analyzed.

\section{Acknowledgments}

This research was conducted as a doctoral dissertation and it was supported by the University of Banja Luka, Faculty of Physical Education and Sport and Sport Institute. Data collection was made possible by permission of staff members and dancers of the Dance Sport Association of Bosnia and Herzegovina who volunteered to participate in this study.

\section{Funding}

The authors declare no funding or conflicts of Interest related to this study. 


\section{Conflict of Interest}

There was no conflict of interest in carrying out this study.

\section{References}

Ambegaonkar, J.P.S.V. Caswell, Winchester, J.B., Shimokochi, Y., Cortes, N., \& Caswell, A.M. (2013). Balance comparisons between female dancers and active nondancers. Research Quarterly for Exercise and Sport, 84(1), 24-29.

Barlow, R. (2017). Proprioception in dance: a comparative review of understandings and approaches to research. Research in Dance Education, 19(2), 1-18.

Batson, G. (2009). Update on proprioception: considerations for dance education. Journal of Dance Medicine Science, 13(2), 35-41.

Bronner, S. (2012). differences in segmental coordination and postural control in a multijoint dance movement: développé arabesque. Journal of Dance Medicine and Science, 16 (1), 3645.

Bruyneel, A.V., Mesure, S., Pare, J.C., \& Bertrand, M. (2010). Organization of postural equilibrium in several planes in ballet dancers. Neuroscience Letters, 485(3), 228-232.

Bruhn, S., Kullmann, N., \& Gollhofer, A. (2004). The effects of sensorimotor training and strength training on postural stabilization, maximum isometric contraction and jump performance. International Journal of Sports Medicine, 25(1), 5660.

Chatzopoulos, D., Doganis, G., \& Kollias, I. (2018). Effects of creative dance on proprioception, rhythm and balance of preschool children. Early Child Development and Care, 189(12), 1943-1953.

Filipa, A., Byrnes, R., Paterno, M.V., Myer, G.D., \& Hewettet, T.E. (2010). Neuromuscular training improves performance on the star excursion balance test in young female athletes. Journal of Orthopaedic \& Sports Physical Therapy, 40(9), 551558.

Hutt, J., \& Redding, E. (2014). The effect of an eyesclosed dance-specific training program on dynamic balance in elite pre-professional ballet dancers: a randomized controlled pilot study. $J$ Dance Med Sci, 18(1), 3-11.
Han, J., Waddington, G., Adams, R., Anson, J., \& Liu, Y. (2016). Assessing proprioception: a crytical review of methods. Journal od Sports and Health Science, 5, 80-90.

Han, J., Anson, J., Waddington, G., \& Adams, R. (2014). Sport attainmant and proprioception. International Journal of Sport Science \& Coaching. 9(1), 159-170.

Hoffman, M., \& Payne, V.G. (1995). The effects of proprioceptive ankle disk training on healthy subjects. Journal of Orthopedic and Sports Physical Therapy, 21(2), 90-93.

Hackney, M. E., \& Earhart, G. M. (2010). Effects of dance on balance and gait in severe Parkinson disease: a case study. Disability and Rehabilitation, 32(8), 679-684.

Esen, A., Rudarli Nalcakan, G., \& Varol, S.R. (2013). Joint position sense in Turkish professional ballet dancers. Nigde University Journal of Physical Education and Sport Sciences, 7(1), 61-68.

Golomer, E., Bouillette, A., Mertz, C., \& Keller, J. (2008). Effect of mental imagery styles on shoulder and hip rotations during preparation on pirouettes. Journal of Motor Behaviour, 40(4), 281-290.

Islam, M.M., Nasu, E., Rogers, M.E., Koizumi, D., Rogers, N.L., \& Takeshima, N. (2004). Effect of combined sensory and muscular training on balance in Japanese older adults. Preventive Medicine, 39 (6), 1148-1155.

Jola, C., Angharad, D., \& Haggard, P. (2011). Proprioceptive integration and body representation: insights into dancer's expertise. Experimental Brain Research, 213, 257-265.

Lieberman, D.E. (2012). What we can learn about running from barefoot running. Exercise and Sport Sciences Reviews, 40(2), 63-72.

Ljubojevic, A., Bijelic, S., Sebic, L., \& Gerdijan, N. (2017). Effects of proprioceptive training od dance sport performance. $8^{\text {th }}$ International Scientific Conference on Kinesiology - Science in Dance. University of Zagreb. Faculty of Kinesiology, Croatia, 809-814.

Ljubojević, A., Bijelić, S., Radisavljević, L., Uzunović, S., \& Pantelić, K. (2012). Effects of proprioceptive training on balance skills among dance sport dancers. Facta Universitatis Series: Physical Education and Sport, 10(3), 257-266. 
Myer, G.D., Ford, K.R., McLean, S.G., \& Hewett, T.E. (2006). The effects of plyometric versus dynamic stabilization and balance training on lower extremity biomechanics. American Journal of Sports Medicine, 34(3), 445-455.

Myer, G.D., Ford, K.R., Palumbo, O.P., \& Hewett, T.E. (2005). Neuromuscular training improves performance and lower-extremity biomechanics in female athletes. The Journal of Strength and Conditioning Research, 19(1), 51-60.

Miura, A., Kudo, K., Ohtsuki, T., \& Kanechisa, H. (2011). Coordination modes in sensorimotor synchronization of whole-body movement. a study of street dancers and nondancers. Human Movement Science, 30(6), 1260-1271.

Malliou, P., Amoutzas, K., Theodosiou, A., Gioftsidou, A., Mantis, K., Pylianidis, T., \& Kioiumourtzoglou, E. (2004). Proprioceptive training for learning downhill skiing. Perceptual and Motor Skills, 99(1), 149-154.

Minton, S., \& McGill, K. (2011) A study of the relationship between teacher behaviour and student performance on a spatial kinaesthetic awareness test. Dance Research Journal, 30(2), 3952.

Metikoš, D., Hofman, E., Prot, F., Pintar, Ž., \& Oreb, G. (1989). Mjerenje bazičnih motoričkih dimenzija sportista (Measurement of basic motor dimensions of athletes). Zagreb, Faculty of Kinesiology, University of Zagreb [In Croatian].

Metikoš, D., Marković, G., Prot, F., \& Jukić, I. (2003). Latent structure of agility obtained by a battery of tests. Kinesiology, 35(1), 14-29.

Rosker, J,. \& Sarabon, N. (2010). Kinaesthesia and methods for its assessment: literature review. Sport Science Review, 19, 165-208.

Rein, S., Fabian, T., Zwipp, H., Rammelt, S., \& Weindel, S. (2011). Postural control and functional ankle stability in professional and amateur dancers. Clinical Neurophysiology, 122(8), 1602-1610.

Sheppard, J. M., \& Young, W.B. (2006), Agility literature review: classifications, training and testing. Journal of Sports Sciences, 24 (9), 919-932.

DaSilva Borgers, E.G., de Souza Vale, R.G., Cader, S.A., Leal, S., Miguel, F., Pernambuco, C.S., \& Dantas, E.H.M. (2014). Postural balance and falls in elderly nursing home residents enrolled in a ballroom dancing program. Arch Gerontol Geriatr, 59(2), 312-316.

Srdic, V., \& Bajric, O. (2015). Changes of dancers funcional abilities under the influence of proprioceptive training and training with the rope. Internationa Conference: Современные технологии воспитания культуры здоровья участников образовательного процесса. At: Iuneu̧к. [In Russian]

Šimek Šalaj, S., Milanović, D., \& Jukić, I. (2007). The effects of proprioceptive training on jumping and agility performance. Kinesiology, 39(2), 131141.

Tekin, D., Agopyan, A., \& Baltaci, G. (2018). Balance training in modern dancers: proprioceptiveneuromuscular training vs kinesio taping. Medical Problems of Performing Artists, 33(3), 156165.

Verstegen, M., \& Marcello, B. (2001). Agility and coordination. In B. Foran (Ed.), High performance sports conditioning (pp. 139-165). Champaign, IL: Human Kinetics.

WDSF. (2020, August 6). Competition - The performance. Retrived from https://www.world dancesport.org/About/Competition 


\section{APENDIX 1 - Some of the exercise of the proprioceptive training}

The duration of the proprioceptive program is twelve weeks. Over the course of one week, there are three trainings distributed on Monday, Wednesday and Friday. The implementation of each class is preceded by dancers' warming up for 10 minutes. During one training, there are maximally $3-4$ exercises. The duration of the proprioceptive training does not exceed 30 minutes. In total, there were 36 trainings. The table below describes some examples of the used exercises in one week of proprioceptive program.

\begin{tabular}{|c|c|c|}
\hline Monday & Wednesday & Friday \\
\hline $\begin{array}{l}\text { Performing the move circumference on } \\
\text { a T-board with both legs, opened eyes, } \\
\text { the board set widthwise: } \\
\text { - Wide posture, back and forth } \\
\text { - Narrow posture, back and forth } \\
\text { - Stretched legs } \\
\text { - Squatted legs } \\
\text { Dynamic stabilization exercises: } \\
\text { - Landing from one leg onto another and } \\
\text { keeping balance for } 3 \text { seconds with open } \\
\text { eyes } \\
\text { - Landing from one leg onto another and } \\
\text { keeping balance for } 3 \text { seconds with } \\
\text { closed eyes }\end{array}$ & $\begin{array}{l}\text { Both legs balancing on a rocker } \\
\text { board, with open eyes: } \\
\text { - Diagonal posture, the right before the } \\
\text { left } \\
\text { - Diagonal posture, the left before the } \\
\text { right } \\
\text { - Legs-apart posture }\end{array}$ & $\begin{array}{l}\text { Dynamic stabilization } \\
\text { exercises: } \\
\text { - In the set rumba rhythm, three } \\
\text { quick spin moves with keeping } \\
\text { the balancing position at the } \\
\text { end of the moving (the spins } \\
\text { are performed in one tact, first } \\
\text { to one and then to the other } \\
\text { side) }\end{array}$ \\
\hline
\end{tabular}

